\title{
A Front Tracking Model of the MAXUS-8 Microgravity Solidification Experiment on a Ti-45.5at.\% Al-8at.\%Nb Alloy
}

\author{
Robin Mooney \\ Technological University Dublin, robin.mooney@mydit.ie \\ Shaun McFadden \\ shaun.mcfadden@tudublin.ie \\ Marek Rebow \\ Technological University Dublin, marek.rebow@tudublin.ie
}

See next page for additional authors

Follow this and additional works at: https://arrow.tudublin.ie/engmecdesignart

Part of the Mechanical Engineering Commons, Metallurgy Commons, and the Other Engineering Science and Materials Commons

\section{Recommended Citation}

R. P. Mooney, S. McFadden, M. Rebow, and D. J. Browne. (2012) A front tracking model of the MAXUS-8 microgravity solidification experiment on a Ti-45.5at.\% Al-8at.\%Nb alloy, IOP conference series. Materials science and engineering, vol. 27, no. 1, p. 12020, 2012. doi:10.1088/1757-899X/27/1/012020

This Article is brought to you for free and open access by the School of Mechanical and Design Engineering (old) at ARROW@TU Dublin. It has been accepted for inclusion in Articles by an authorized administrator of ARROW@TU

Dublin. For more information, please contact

arrow.admin@tudublin.ie, aisling.coyne@tudublin.ie, gerard.connolly@tudublin.ie.

Funder: European Space Agency / Enterprise Ireland

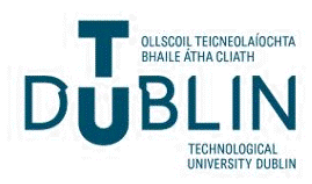




\section{Authors}

Robin Mooney, Shaun McFadden, Marek Rebow, and David J. Browne 
A front tracking model of the MAXUS-8 microgravity solidification experiment on a Ti-45.5at.\% Al-8at.\%Nb alloy

This content has been downloaded from IOPscience. Please scroll down to see the full text. 2012 IOP Conf. Ser.: Mater. Sci. Eng. 27012020

(http://iopscience.iop.org/1757-899X/27/1/012020)

View the table of contents for this issue, or go to the journal homepage for more

Download details:

IP Address: 134.226.144.144

This content was downloaded on 08/04/2016 at 13:27

Please note that terms and conditions apply. 


\title{
A front tracking model of the MAXUS-8 microgravity solidification experiment on a Ti-45.5at.\% Al-8at.\% $\mathrm{Nb}$ alloy
}

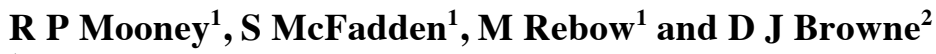 \\ ${ }^{1}$ College of Engineering and Built Environment, Dublin Institute of Technology, \\ Bolton Street, Dublin 1, Ireland \\ ${ }^{2}$ School of Electrical, Electronic, and Mechanical Engineering, University College \\ Dublin, Dublin 4, Ireland \\ E-mail: robin.mooney@mydit.ie
}

\begin{abstract}
On $26^{\text {th }}$ March 2010 the MAXUS-8 sounding rocket was launched from the Esrange Space Center in Sweden. As part of the Intermetallic Materials Processing in Relation to Earth and Space Solidification (IMPRESS) project, a solidification experiment was conducted on a Ti-45.5at.\% Al-8at.\% Nb intermetallic alloy in a module on this rocket. The experiment was designed to investigate columnar and equiaxed microstructures in the alloy. A furnace model of the MAXUS 8 experiment with a Front Tracking Model of solidification has been developed to determine the macrostructure and thermal history of the samples in the experiment. This paper gives details of results of the front tracking model applied to the MAXUS 8 microgravity experiment. A model for columnar growth is presented and compared to experimental results for furnace A of the experiment module.
\end{abstract}

\section{Introduction}

The IMPRESS project was set up to gain an improved understanding of the material processing, microstructure, and final properties of intermetallic alloys. One objective of the project was to develop and test TiAl cast turbine blades for use in aero-engines and stationary gas turbines [1]. TiAl alloys have the potential to replace conventional nickel superalloys due to their relatively low density and good mechanical properties operating in high temperature environments. Processing this alloy is made difficult given its high liquidus temperature and because of the high reactivity of molten Ti. Other common casting problems include; shrinkage porosity, hot tearing, and misrun [2]. Therefore, IMPRESS aimed to develop and improve the melting technique and casting process for industry to achieve high quality cast turbine blades.

Microgravity experiments are unique in that the complicating effects of gravity on solidification are suppressed. In terrestrial casting experiments (in a $1 \mathrm{~g}$ environment) thermal and solutal transport, due to natural convection, produce sedimentation and macro-segregation. By carrying out microgravity experiments and comparing to identical ground based experiments it is possible to distinguish the effect of these phenomena from others, common to both environments, and therefore refine and improve theoretical models for casting [3]. 
Columnar to Equiaxed Transition (CET) is one event in casting that is of particular interest. A CET is said to occur when the progress of constrained (columnar) grain growth is blocked by the nucleation and subsequent growth of unconstrained (equiaxed) grains. A detailed account of theory and models for CET was given by Spittle [4]. In normal casting scenarios either a fully columnar or equiaxed grain structure is desired so that consistent mechanical properties are achieved throughout the casting. For example, castings with a columnar grain structure are used in directionally solidified turbine blades, or to reduce creep at high temperatures. Fully equiaxed cast components are used for applications where strength is important, to improve feeding, or reduce the possibility of hot tearing. It is therefore important to understand the conditions that produce a CET in order to avoid it as necessary. Hunt [5] developed an analytical model that predicts columnar, equiaxed, or mixed microstructure for steady state directional solidification. According to this model the microstructure is determined by the pulling velocity and temperature gradient in the sample. This analysis is useful to treat results of casting experiments.

The MAXUS-8 sounding rocket was launched on the 26th March 2010 from the Esrange Space Center launching facility [6]. The rocket carried four experiment modules, one of which was a furnace module dedicated to the investigation of the solidification of Ti-Al-Nb alloys as part of the IMPRESS project. A furnace model of the experiment has been developed that uses a Front Tracking Model to determine the solidification and thermal histories of the samples in the experiment using an inverse heat transfer calculation method. The model has been successfully applied to a similar solidification experiment onboard the MAXUS-7 sounding rocket [7], carrying AlSi alloy samples. This paper details the results of the front tracking model as applied to the MAXUS-8 experiment for Furnace A and provides analysis of the same.

\section{Experiment}

A detailed description of the MAXUS-8 experiment was given by Mooney et. al. [8]. The module contained four integrated furnaces working independently of each other. Each furnace was equipped with three in-line resistance heaters. Two samples of Ti-Al-Nb were tested, one refined with boron (Ti-44at.\%Al-7.5at.\%Nb-2.5at.\%B, in furnaces B and D) and one without grain refinement (Ti45.5at.\%Al-8at.\% Nb, in furnaces $\mathrm{A}$ and $\mathrm{C}$ ). Figure 1 shows the alloy sample (diameter of $8 \mathrm{~mm}$, $165 \mathrm{~mm}$ long) enclosed in an yttrium oxide $\left(\mathrm{Y}_{2} \mathrm{O}_{3}\right)$ crucible, wrapped in a tantalum sleeve and cartridge.

Figure 1. Schematic of furnace set-up showing three heaters, adjacent thermocouples (T1, T2, T3) and the centreline thermocouple (T4) with plot of typical temperature gradients G1 and $\mathrm{G} 2$ between the heaters. The sample alloy (in black) is wrapped in an yttrium oxide crucible and Tantalum cartridge.

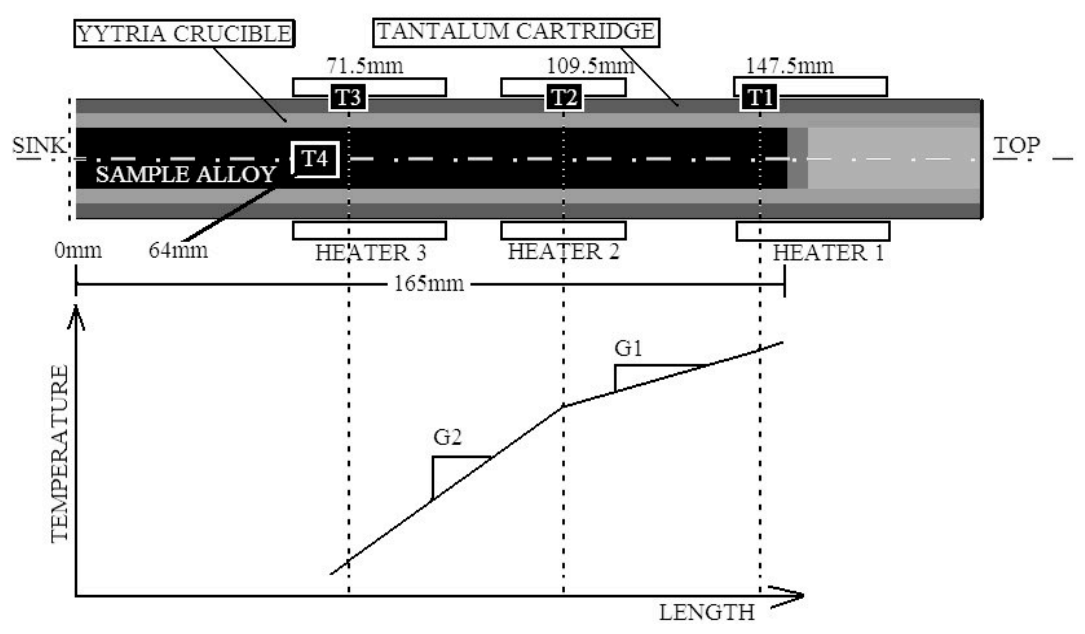

The cartridge was separated from the heater compartment by helium to reduce potential oxygen contamination and the heater compartment was Argon filled. The module had no moving parts. Each furnace had three thermocouples (T1, T2, \& T3) fixed into the tantalum cartridge to measure temperature at intervals adjacent to each heater, another (T4) measured temperature in an unmelted 
section of the sample at the sample axis. The data retrieved from the experiment included complete thermal histories at each thermocouple location.

The furnace was capable of melting a portion of the alloy $(65 \mathrm{~mm})$ with a maximum achievable temperature of $1700^{\circ} \mathrm{C}$, and subsequently cooling it within a 12 -minute microgravity time window. The sample was directionally solidified in two phases of cooling so that a predetermined temperature gradient and solidification front velocity was achieved in each phase using a power-down technique. This is where temperatures gradients between the heaters are maintained during cooling by applying specific set-point temperatures via PID heater controllers.

\section{Experiment Results}

This paper deals with results from the Furnace A experiment carrying an unrefined Ti-45.5at.\%Al8 at. $\% \mathrm{Nb}$ alloy sample, $8 \mathrm{~mm}$ in diameter and $165 \mathrm{~mm}$ long. The thermal history retrieved for this furnace is shown in figure 2 . The temperatures at the four thermocouples are plotted against time from launch, the cooling phases I and II and their relative times from launch are shown. A detailed microstructure analysis was carried out by scanning-electron-microscope (SEM). A micrograph for the Furnace-A sample is shown in figure 3 . Note the notch in the sample denotes a marker at $130 \mathrm{~mm}$ from the sink end of the sample. A clear columnar dendrite pattern (white elongated shapes) is visible in the radial direction here.

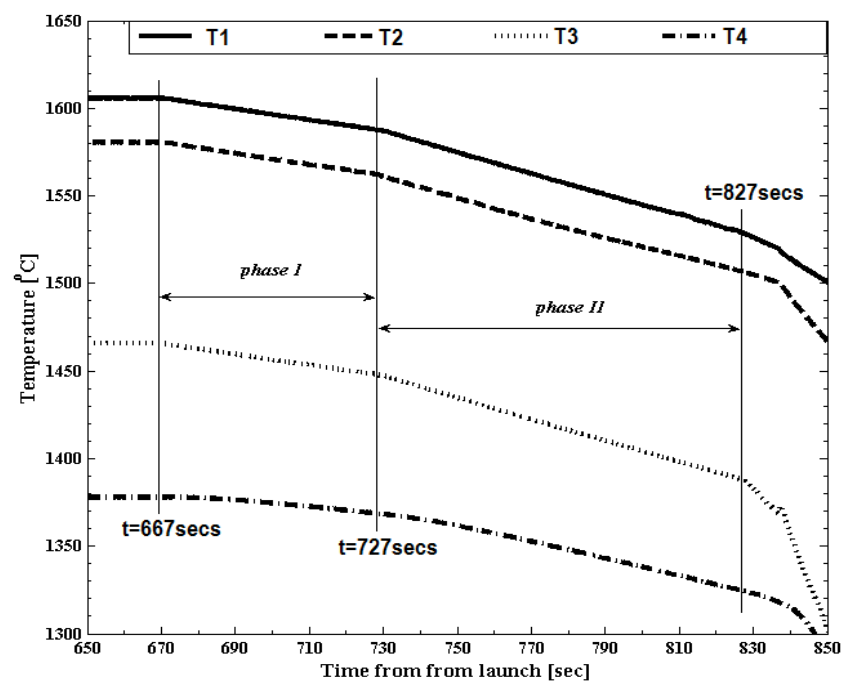

Figure 2. Thermal history for Furnace A

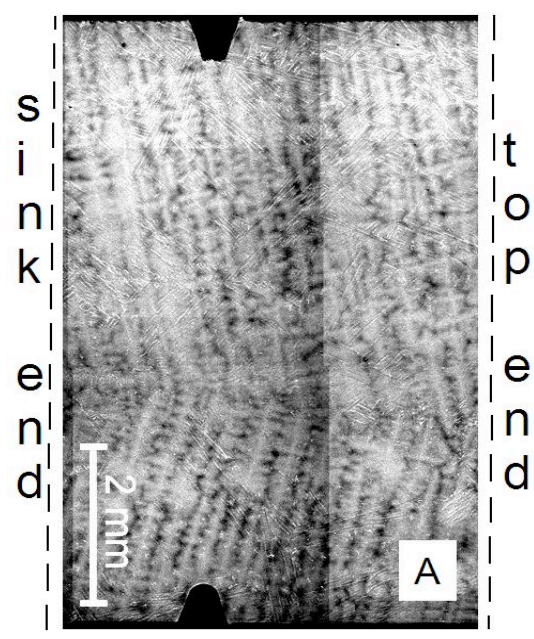

Figure 3. SEM micrograph of the Furnace A sample. The columnar grains are visible in white. (Image courtesy of ACCESS e.V., Germany).

Figure 4 shows how the growth pattern developed. The columnar dendritic growth was initially in the axial direction. It is clear that the radial growth became dominant as the solidification progressed along the sample length. This transition to radial columnar growth is observed at approximately $123 \mathrm{~mm}$ along the sample, leaving a $\mathrm{V}$-shape (in white dashed lines) at the transition. The notch in this figure denotes the $130 \mathrm{~mm}$ marker from the sink end of the sample. There was no CET observed in the unrefined samples.

\section{Model Details}

The Front Tracking Model (FTM) for alloy castings that solidify with a dendritic structure has been validated by McFadden and Browne [9] using an orthogonal grid domain. The model was subsequently applied to the IMPRESS furnace design by McFadden and Browne [10] (prior to its 
initial launch) using an axisymmetric domain, in order to aid the plans for the microgravity experiment on MAXUS-8. In FTM dendritic alloy solidification is modeled at the scale of the grain envelope $(\mathrm{mm})$ and is therefore convenient for modeling at the typical scale of a casting $(\sim \mathrm{m})$. The model now serves as a useful tool in disseminating the results retrieved post-launch.

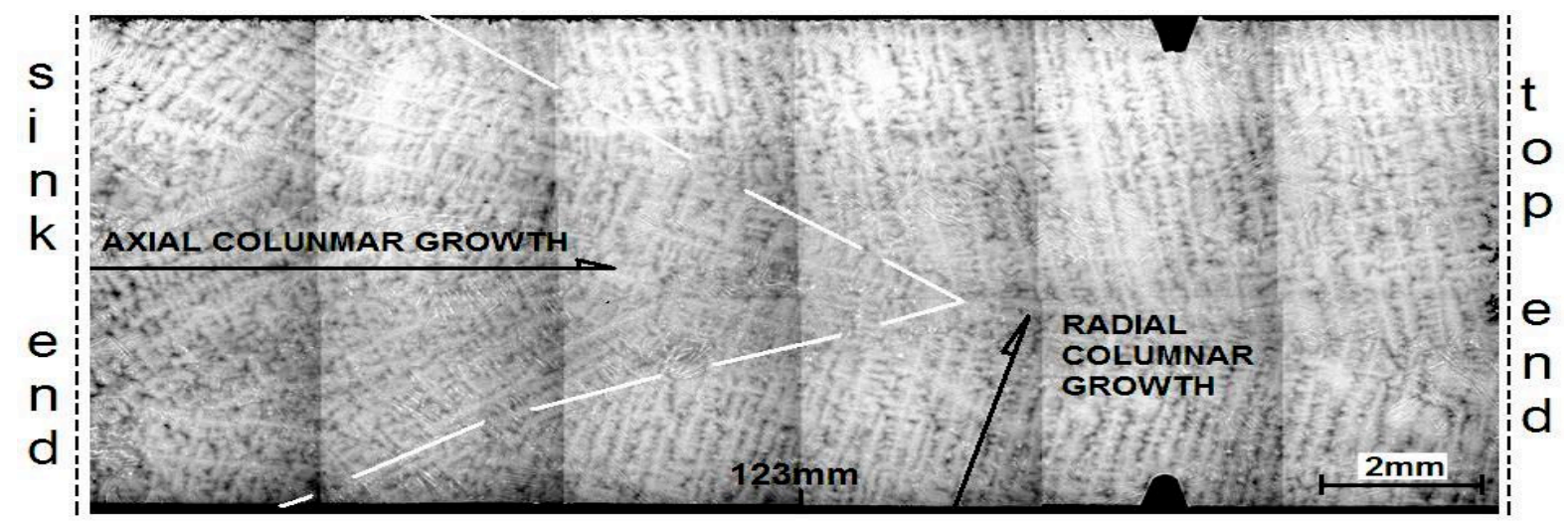

Figure 4. Axial to radial columnar growth at approximately $x=12.3 \mathrm{~cm}$.

(Image courtesy of ACCESS e.v., Germany).

\subsection{Nucleation}

It was clear from inspection of the grain pattern of the Furnace A sample that nucleation took place at the mould walls. Markers at grid intersections were placed along the walls of the mould to represent heterogeneous nucleation sites. The typical progress of the markers is outlined in figure 5 . Once a set level of undercooling is reached the site is activated. The average nucleation undercooling was assumed to be $1 \mathrm{~K}$.

\subsection{Dendrite Kinetics}

The magnitude of advance of a marker is calculated as a function of undercooling as given by Rebow et. al. [11]. This is the dendrite tip velocity and is given equation 1.

$$
\left|V_{\text {tip }}\right|=C \Delta T^{n}
$$

Where $C$ is a constant of proportionality with dimensions $\left[\mathrm{cm} \mathrm{s}^{-1} \mathrm{~K}^{-\mathrm{n}}\right]$ and a value of $2.63 \times 10^{-4}$, and $n$ is the dimensionless undercooling index with a value of 2.79 . The direction of growth is normal to the liquid-mush interface and is given by the line that bisects the angle made between the marker and its neighbour markers.

\subsection{FTM Details}

A complete account of the FTM algorithm used is given by Browne and Hunt [12]. This algorithm was adapted to model the columnar grain pattern observed in the solidified sample of Furnace A. In this model the grains grow with a preferred orientation into the casting from the mould walls until impingements with other grains occur. The solidification fronts are given by computational markers at the intersections with the gridlines. Piecewise linear segments between the markers determine the columnar front by joining the estimated location of the dendrite tips. Figure 5 outlines the typical evolution of grain growth.

Once a nucleation site is activated it is permitted to grow. At each time step the undercooling and hence dendrite tip velocity is calculated. The front marker locations are then updated and a new front envelope is determined for the next time step. The hatched area in figure 5 represents the mushy zone and the solid areas represent liquid regions. It is clear that nucleation sites 1 and 2 have nucleated at the same time, followed by sites 3, 4, and 5 at subsequent times. Site 6 has not yet nucleated. The grains formed by site 1 and 2 have impinged. The insert shows a zoomed in view of one of the grains. 
This shows how the front markers separate the liquid and mushy zones to give a captured volume, shown hatched.

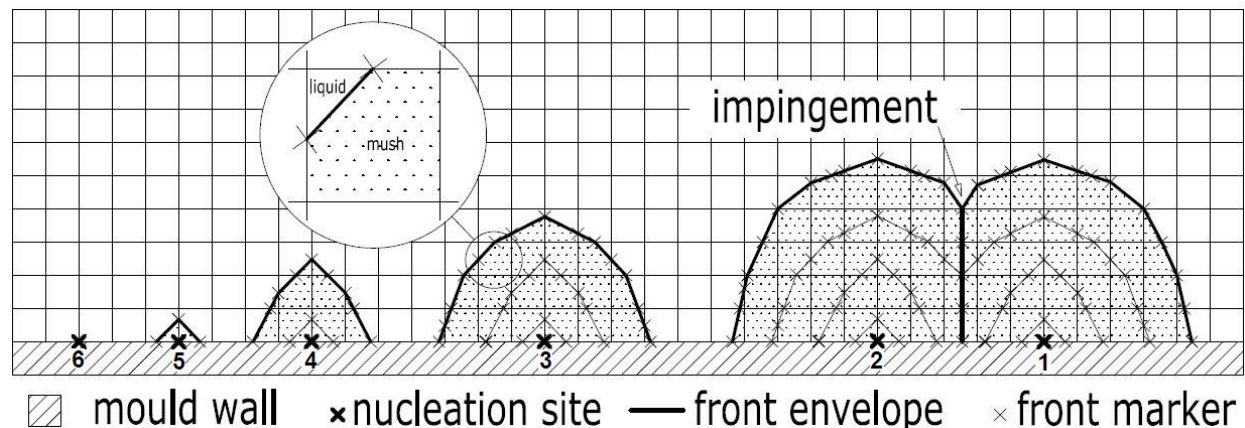

Figure 5. Evolution of nucleation sites and front envelope growth

\subsection{Heat Equation}

The heat equation is solved over a 2-D axisymmetric domain using an explicit finite difference control volume method. A source term, $E$, is included to manage the latent heat released as given in equation (2).

$$
\frac{\partial}{\partial t}\left(\rho C_{p} T\right)=\nabla(k \nabla T)+E
$$

Where $\rho$ is the density, $C_{p}$ is the specific heat capacity, $T$ is the temperature, $k$ is the conductivity, and $E$ is the latent heat. The latent heat released is a function of solid fraction $g_{s}$, determined by equations (3), (4), and (5).

$$
\begin{array}{lll}
g_{s}=0.0 & \forall & T \geq T_{L} \\
g_{s}=\frac{T_{L}-T}{T_{L}-T_{S}} & \forall & T_{L}>T>T_{S} \\
g_{s}=1.0 & \forall & T \leq T_{S}
\end{array}
$$

Where $T_{L}$ and $T_{S}$ are the liquidus and solidus temperatures for the alloy. Within these temperatures solid fraction is a linear function of temperature. The latent heat is then given by equations (6), (7), and (8).

$$
\begin{aligned}
& E=E_{a}+E_{t} \\
& E_{a}=\frac{\left(d-d_{0}\right) \cdot g_{S}^{0} \cdot L}{\Delta t \cdot \Delta x \cdot \Delta y} \\
& E_{t}=\frac{d_{0} \cdot\left(g_{S}-g_{S}^{0}\right) \cdot L}{\Delta t \cdot \Delta x \cdot \Delta y}
\end{aligned}
$$

Where $d$ is the captured volume of mush, in a control volume, at the end of a time step (time $=t+\Delta t)$, and $d^{0}$ is the captured volume of mush at the beginning of a time step (time $=t$ ). Similarly, $g_{S}{ }^{0}$ is the solid fraction at the beginning of a time step and $g_{S}$ is the solid fraction at the end of a time step. $L$ is the latent heat of fusion per unit volume. $\Delta t$ is the time step. $\Delta x$ and $\Delta y$ are the $\mathrm{x}$ and y direction grid resolutions. $E_{a}$ then gives the latent heat released due to the advancement of a front over one time step 
in a control volume, and $E_{t}$ is the latent heat released due to the thickening of the dendrites after the front has passed through a control volume.

\subsection{Thermophysical Properties}

The model uses data extracted from Egry et. al. [13] for the alloy. Thermophysical properties such as density, conductivity, and specific heat are given by polynomial functions of temperature for the liquid and solid alloy. For example, the thermal diffusivity for the solid alloy is given by:

$$
k_{T i-A l-N b}=\left(-3.01 \cdot 10^{-9} \mathrm{~T}^{3}+4.30 \cdot 10^{-7} \mathrm{~T}^{2}+5.18 \cdot 10^{-3} \mathrm{~T}+5.36\right) 10^{-6}\left[\mathrm{~m}^{2} / \mathrm{s}\right]
$$

Also, the model relates thermal conductivity to phase fraction in order to deal with the multiphase aspect of the problem.

\section{Simulation Results}

The simulated thermal history at the thermocouple locations is shown in figure 6 . The dashed lines are the simulated temperatures and the solid lines are the experiment data. The two phases of cooling are shown. Figure 7 shows the simulated axial temperature at various times after launch. The liquidus temperature line for the alloy is shown.

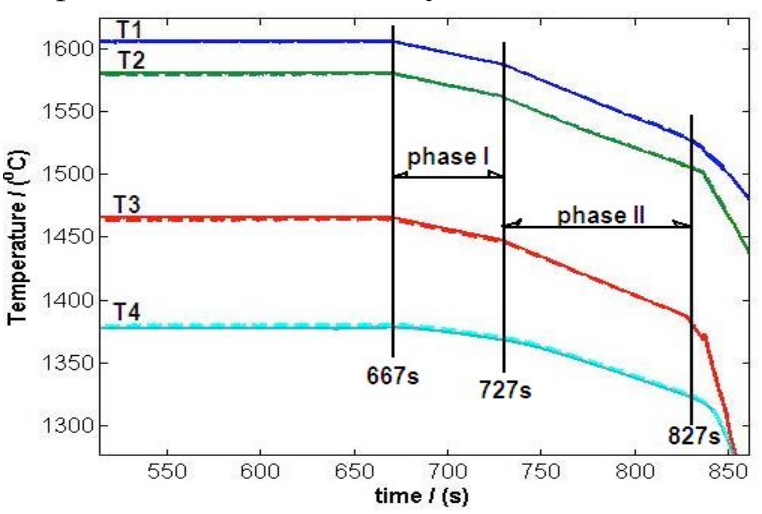

Figure 6. Thermal history of thermocouples T1, $\mathrm{T} 2, \mathrm{~T} 3, \& \mathrm{~T} 4$ for Furnace A (dashed line is simulated, solid line is experiment data) with the two phases of cooling shown.

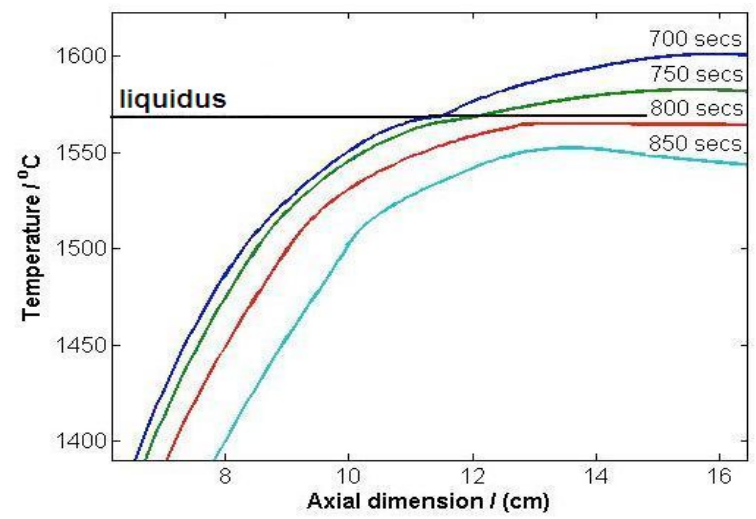

Figure 7. Simulated temperature profiles along the axis of the Furnace A sample at various times after launch.

Figure 8 shows the simulated columnar growth pattern from nucleation at the mould walls and initial solid, through impingement with other grains, to final solidification. Figure 9 shows the isotherm pattern corresponding to each of the images in the previous figure.

\section{Discussion}

There was no CET present in the unrefined alloy samples from the experiment. The microstructure observed was fully columnar. There was no evidence of equiaxed nucleation in the bulk liquid. Therefore the number of potential equiaxed nucleation sites must have been limited. For example, it could then be argued that there was very little fragmentation occurring. It should be noted however that from figure 7 the temperature gradient in the upper region of the sample was low and should therefore have been conducive to equiaxed growth. 

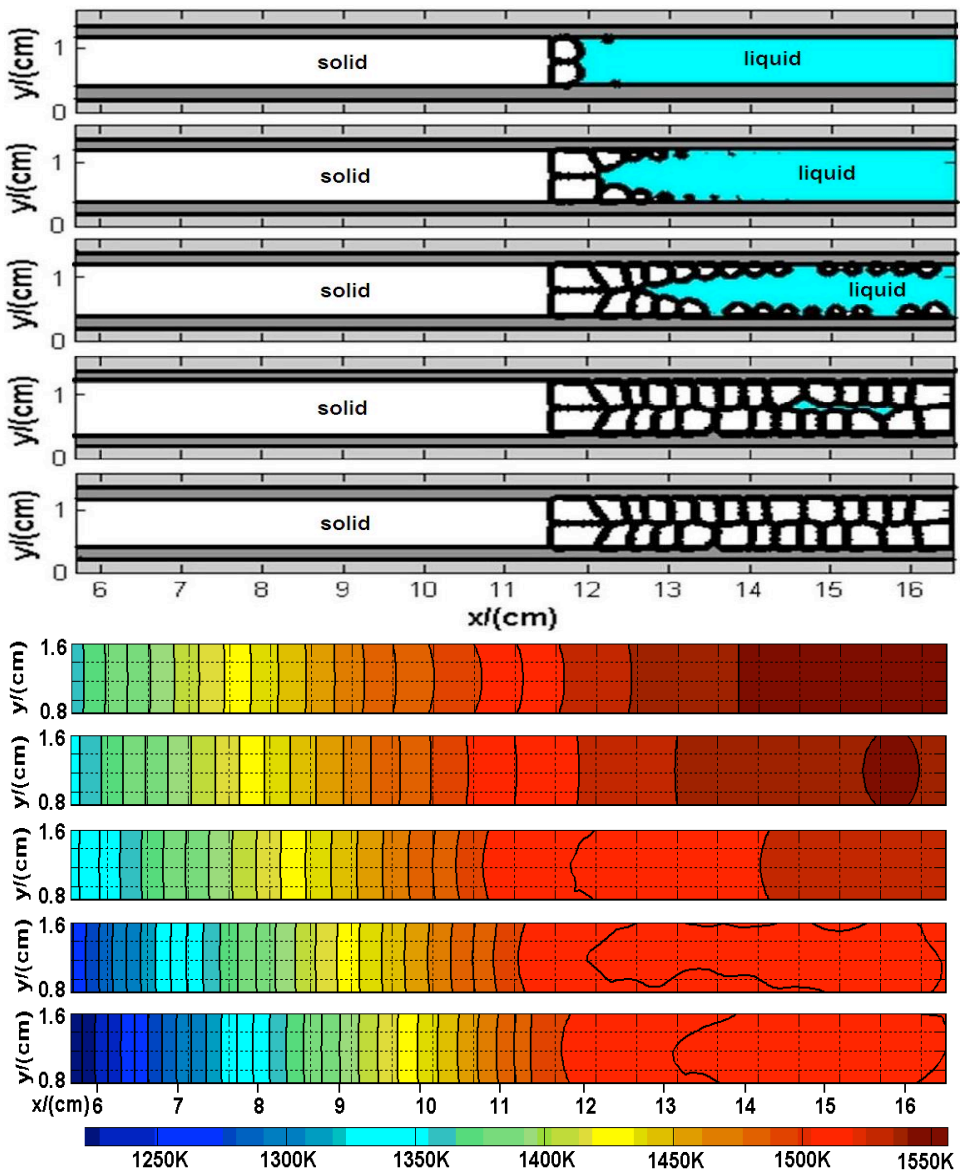

Figure 8. Simulated columnar growth pattern. The left hand side is the solid region and the liquid and growing columnar fronts are on the right hand side. The images show the simulation at 50 seconds intervals of time. The top image is at 700seconds after launch and the bottom image is 900 seconds after launch. A V-shape pattern at $12.3 \mathrm{~cm}$ (approximately) is noticeable in the final solidified image representing the axial to radial columnar growth transition.

Figure 9. Simulated isotherm pattern observed at times corresponding to images in figure 8 . Note the curved isotherms developing at $12 \mathrm{~cm}$ in the final image.

The columnar microstructure observed was initially axial in orientation, however radial columnar growth tended to dominate the pattern at approximately $12.3 \mathrm{~cm}$. The probable reason for this occurrence was because of larger than expected heat loss in the regions between the heaters leading to curved isotherms, as displayed in figure 9. The model closely estimates the transition from axial to radial columnar growth, as shown in the fully solidified image of figure 8 . The thermal history generated in the simulation is matched closely with the experiment data, as shown in figure 6 . This was to be expected, as the inverse heat transfer method for calculating the heat flux at the heaters was determined from the experiment data.

The linear assumption used to calculate the solid fraction is simplistic. It would be more accurate to use a non-linear function here based on the consideration of microsegregation [14]. The main effect of this assumption will be on the rate of latent heat release as one moves down into the mushy zone - but the total latent heat released will still be the same. Scheil or Lever type functions for solid fraction could be used. However, considering that we are dealing with a ternary alloy application, either of these relations is quite involved. An advantage of the linear assumption is that it is computationally efficient and avoids the requirement for iteration.

\section{Conclusion}

A working model is presented here for the columnar growth of the alloy. Temperature agreement is good due the inverse heat transfer method used in the model. Columnar growth was observed in the unrefined experiment sample (Furnace A) and the model predicts the axial to radial columnar growth pattern and specifically predicts the point where the radial pattern dominates. There is potential in the model to develop how the heat loss in the region between the heaters is dealt with. 
The dendrite kinetics model used is based on a study of a binary Ti-46at.\%Al alloy. Whilst similar in composition to the IMPRESS alloy, it would be preferable to incorporate a more advanced model for dendrite tip velocity that is based on the Ti-Al-Nb ternary alloy. This would give a better estimation for undercooling levels required for growth. One such model is outlined by Hunziker [15].

There was no CET observed in the unrefined experiment samples, however (as shown in [8]) the refined samples did produce a fully equiaxed structure. This was expected as the boride particles in the refined samples provided numerous sites for equiaxed nucleation to occur. The FTM model can be used to model this type of growth, and indeed a CET if it should occur, as shown by McFadden and Browne [10]. Also an analysis of the temperature gradients and dendrite tip velocities can be carried out to compare with the analytical model of Hunt [5], for directionally solidified castings, where a plot of growth velocity versus temperature gradient distinctly identifies the conditions for columnar and equiaxed growth. Temperature gradient $(G)$ and tip velocity $(V)$ data can be taken from the FTM model to provide a locus of $G-V$ points during solidification, and by superimposing these onto the Hunt diagram one will discover the most likely as cast microstructure, columnar, equiaxed, or CET. This was demonstrated by McFadden et. al. [7]. This approach would be suitable to treat the results from the refined alloy experiments on MAXUS-8.

\section{Acknowledgments}

This research work was funded by The European Space Agency PRODEX programme with the support of the Irish Government and Enterprise Ireland. The authors would like to acknowledge the support of all partners in the IMPRESS project WP4a (especially U. Hecht and S. Rex of ACCESS e.V., Germany, for experimental characterisation) and the Swedish Space Corporation.

\section{References}

[1] Jarvis D J and Voss D 2005 Mater. Sci. Eng. A 413-414 583-591

[2] Wang H, Djambazov G, Pericleous K A, Harding R A and Wickins M 2009 Proc. Modeling of Casting, Welding, and Advanced Solidification Processes XII (Vancouver, BC, Canada, 7-14 June 2009)

[3] Lemoisson F, McFadden S, Rebow M, Browne D, Froyen L, Voss D, Jarvis D J, Kartavykh A V, Rex S, Herfs W, Groethe D, Lapin J, Budenkova O, Etay J and Fautrelle Y 2010 Materials Science Forum 649 17-22

[4] Spittle J A 2006 International Materials Review 51(4) 247-269

[5] Hunt J D 1984 Materials Science and Engineering 65 75-83

[6] http://www.esa.int/esaCP/SEMNVY8I77G_index_0.html

[7] McFadden S, Browne D J, Sturz L and Zimmermann G 2010 Mat. Sci. Forum 649 361-366

[8] Mooney R, Browne D, Budenkova O, Fautrelle Y, Froyen L, Kartavykh A, McFadden S, Rex S, Schmitz B and Voss D 2011 Proc. of the 20th European Space Agency Symposium on European Rocket and Balloon Programmes and Related Research (Hyeres, Provence, France, 22-26 May 2011)

[9] McFadden S and Browne D J 2009 Applied Mathematical Modelling 33 1397-1416

[10] McFadden S and Browne D J 2009 Proc. Modeling of Casting, Welding, and Advanced Solidification Processes XII (Vancouver, BC, Canada, 7-14 June 2009) (TMS:Warrendale 2009)

[11] Rebow M, Browne D J, and Fautrelle Y 2010 Materials Science Forum 649 243-248

[12] Browne D J and Hunt J D 2004 A Fixed Grid Front-Tracking Model of the Growth of Columnar Front and an Equiaxed Grain During Solidification of an Alloy Numerical Heat Transfer, Part B: Fundamentals 45(5) 395-419

[13] Egry I, Brooks R, Holland-Moritz D, Novakovic R, Matsushita T, Ricci E, Seetharaman S, Wunderlich R, and Jarvis D 2007 International Journal of Thermophysics 28 (3) 1026-1036

[14] Flemings M C 1974 Solidification Processing McGraw-Hill New York

[15] Hunziker O 2001 Acta Materialia 49 (20) 4191-420 